\title{
System Design and New Materials for Reversible, Solid-Oxide, High Temperature Steam Electrolysis
}

\author{
Final Scientific Report
}

\author{
Principal Investigator: James A. Ruud \\ Date Report was Issued: December 2007 \\ DOE Award Number: DE-FC36-05GO15025 \\ Name and Address of Recipient Organization: \\ GE Global Research \\ 1 Research Circle \\ Niskayuna, NY 12309 \\ Teaming Members: \\ Northwestern University, Functional Coating Technology, LLC
}




\section{Disclaimer}

"This report was prepared as an account of work sponsored by an agency of the United States Government. Neither the United States Government nor any agency thereof, nor any of their employees, makes any warranty, express or implied, or assumes any legal liability or responsibility for the accuracy, completeness, or usefulness of any information, apparatus, product, or process disclosed, or represents that its use would not infringe privately owned rights. Reference herein to any specific commercial product, process, or service by trade name, trademark, manufacture, or otherwise does not necessarily constitute or imply its endorsement, recommendation, or favoring by the United States Government or any agency thereof. The views and opinions of authors expressed herein do not necessarily state or reflect those of the United States Government or any agency thereof." 


\section{EXECUTIVE SUMMARY}

High temperature solid oxide electrolysis cells (SOECs) offer high electrical efficiency and a potential path to large scale hydrogen production. Solid oxide technology is capable of both power generation and hydrogen production. That makes it possible for the development of a reversible solid-oxide system that can respond to market conditions to produce electricity or hydrogen on demand. When the cost of energy dictates, reversible SOEC capability can enable a solid oxide fuel cell to operate with stored hydrogen as a peak shaving power generation device or an emergency back up power supply.

The proposed program was to develop novel high temperature electrolyzer cell materials and to provide pilot scale designs scalable to $1000 \mathrm{~kg} /$ day utilizing those materials. The novel electrodes and systems designs, while being very efficient for high temperature electrolysis, would also be stable for fuel cell operation. The resulting system would be both a primary hydrogen production unit and a back-up electrical power supply for renewable energy power parks.

Due to limitations on the funding available, a reduced workscope was implemented. A testing methodology was identified for the eventual development of reversible, durable electrode materials. The two main test methods were the button cell test and the oxygen electrode test. The button cell test would evaluate the performance and degradation of full solid oxide cells with dual atmosphere of air and hydrogen-steam. The oxygen electrode test is a test in air that isolates the performance and degradation of the oxygen electrode. It has higher throughput and sensitivity than the button cell test.

A button cell test methodology for reversible performance was developed. Methods for the quantification of steam content were developed and validated. Stability of the measurements over short time periods was demonstrated for measurements in both modes.

An oxygen electrode test structure was designed. A planar geometry specimen with symmetric electrodes was extended to include a reference electrode in order to allow testing under both a forward (power generation) and a reverse (electrolysis) bias. A 3-D finite element model was developed to predict the accuracy of the design for the materials and geometries of interest. Fabrication methods were developed for accurate placement of the reference electrode, working electrode and counter electrode. Accuracies of better than $10 \%$ were predicted. In addition, a method for making electrical contacts that would not introduce experimental error was demonstrated. 


\section{INTRODUCTION}

Solid oxide technology is capable of both power generation and hydrogen production. That makes it possible for the development of a reversible solid-oxide system that can respond to market conditions to produce electricity or hydrogen on demand. The cost of electricity is a large part of the cost of electrolytic production of hydrogen, and the reversible system offers the possibility to produce hydrogen when electricity cost is low and obtain a value from its power generation when the electricity price is high. Te electrical input to a high temperature steam electrolysis system is lower than that for a low temperature system, which helps reduce the feedstock costs.

Two barriers to realizing the potential of reversible solid-oxide hydrogen production are the system design and the reversibility of the materials. Because the reversible system has balanceof-plant components for both power generation and electrolysis mode, it has a higher capital cost than a dedicated single mode system. Furthermore, the capacity factor in either mode is reduced from that for a single mode system. Innovative system designs that can maximize the total value of the hydrogen and electricity production while minimizing the capital and operating costs are needed.

System capital costs are highly sensitive to the performance and durability of the solid-oxide materials, in particular to the electrode materials. High current density (low area-specificresistance) is desired to reduce stack size and to reduce feedstock cost in electrolysis mode. Low degradation rates are needed to reduce stack replacement costs. The baseline electrode material set for solid-oxide-fuel-cell (SOFC) power generation is lower performing and has higher degradation when used in electrolysis mode compared with fuel cell mode. Therefore, novel materials that have high performance in both modes and reduced degradation rates are required to make reversible solid-oxide hydrogen production feasible.

The proposed program was to develop a pilot scale, reversible SOEC system design capable of $1000 \mathrm{~kg} /$ day hydrogen production at $\$ 2 / \mathrm{kg}$ based on new, low-cost, reversible solid oxide. Electrode materials requirements would be derived from the system design. The performance and durability of ceramic-based electrodes would be enhanced by the discovery of novel electrocatalysts screened specifically for electrolysis operation. Electrode-supported thinelectrolyte cells would be developed based on the ceramic electrodes. Rapid optimization of the electrode microstructures in electrolyzer cells made from the new materials would be made possible by advanced characterization tools for composite structures and interfaces, new accelerated tests of electrochemical performance, and identification of electrolysis performance and failure mechanisms. The performance and durability operating space for the optimized reversible SOECs would be fully mapped for inputs into the system performance models. A pilot plant design with the operating mission profiles would result.

Because of reduced funding, the program workscope was limited to the development of testing methods for the eventual design of reversible, robust electrode materials. Two test methods were identified: a dual-atmosphere button cell test for evaluation of both hydrogen and oxygen electrodes and a single atmosphere method for rapidly evaluation oxygen electrode materials. 


\section{RESULTS}

\subsection{Electrode materials}

In spite of the large technical advances in materials and systems for solid oxide fuel cells (SOFCs), little attention has been given to their operation as high temperature steam electrolyzers. The materials used in state-of-the-art solid oxide fuel cells are not fully reversible because they lack the required performance and durability in electrolysis mode. There are no integrated system designs that fully utilize the ability to produce hydrogen and electricity reversibly to optimize the system costs.

A common SOFC materials set for electrode-supported fuel cells includes a nickel/yttriastabilized-zirconia (YSZ) hydrogen electrode, a YSZ electrolyte and a lanthanum-strontiummanaganate (LSM)/ YSZ oxygen electrode. These materials have demonstrated long term performance in thick-electrolyte, tubular SOFCs, and they have shown efficient fuel cell operation in planar, thin-electrolyte fuel cell stacks as large as $10 \mathrm{~kW}$ [1] and for durations greater than 6000 hours [2]. Careful optimization of the electrode microstructures has shown improvements in power density of up to a factor of 4 over unoptimized systems [3,4].

The baseline materials are capable of limited operation for high temperature steam electrolysis [5,6]. Measurements at GE Global Research on small button cells (Fig. 2-1) indicate that it is possible for the same cell to run current in both directions for power generation and electrolysis. However, these materials are not adequate for cost-effective hydrogen production because they lack the requisite performance and the durability for large-scale systems.

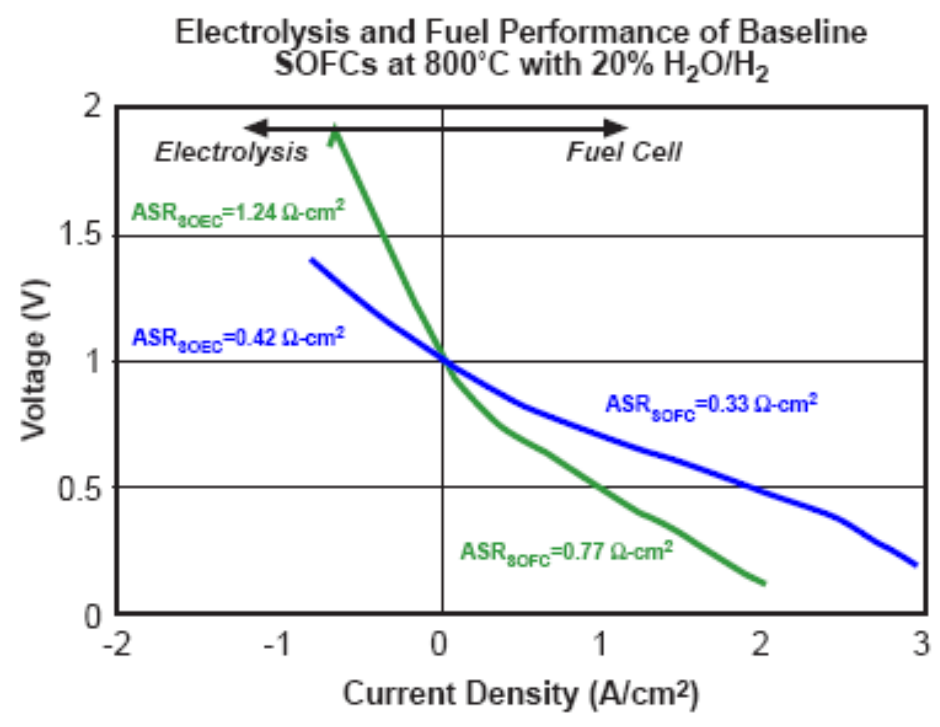

Figure 2-1. Performance curve of button cells with two different hydrogen electrodes from the baseline materials set, and the associated area-specific-resistances (ASRs). 
The electrochemical performance of a solid-oxide system is characterized by the area-specificresistance (ASR). Solid oxide electrolysis cells with very low ASRs produce high current densities at a specified operating voltage. High current density systems are required to minimize the capital costs required to produce hydrogen. The materials and microstructures in a solid oxide cell must be engineered to have low ohmic and polarization ASRs. The ASR values for two cells having different electrode microstructures made from the baseline materials set as shown in Fig.2-1. ASR values are higher for electrolysis than for power generation for these materials [7]. In electrolysis mode, the ASRs are too high for efficient hydrogen production.

Several problems have been reported for using conventional LSM oxygen-electrode materials in electrolysis mode [8]. It was found that anodic polarization (i.e. electrolysis operation) increased the LSM polarization resistance, whereas cathodic polarization (normal SOFC operation) decreased the resistance [9]. This effect has been attributed to partial reduction of the LSM surface and the production of oxygen vacancies in LSM [10].

A substantial barrier to reversible operation with these materials is that the durability of the oxygen-electrode is very low under electrolysis operation [11]. Experiments at GE with symmetric LSM-YSZ electrodes under constant current densities of $0.5 \mathrm{~A} / \mathrm{cm}^{2}$ have shown that the anodic electrode can fully delaminate from the electrolyte in as short as five days. Others have reported similar behavior [7].

New electrode materials specifically optimized for operation in electrolysis mode are required. They should have low electrolysis and power generation ASRs and long life under the dual operating modes. Their performance and durability should be validated over the system design space.

\subsection{Button cell test method development}

SOEC button cells are capable of testing performance and durability of the combined materials set of oxygen-electrode, electrolyte and hydrogen-electrode. Voltage-current relationships can be measured as a function of temperature, gas flows, and steam content to produce performance maps typical of local elements of a large stack. A test rig was modified to allow the use of humidified hydrogen for electrolysis in the range from 3\% to $80 \%$ steam. The bubbler-type humidifiers were calibrated to produce the desired steam levels. A humidified stream was directed through a condenser and the mass of water was measured over a specified time. Good linearity of the bubbler performance was observed over the desired range of gas flow rates.

A second check on the steam content was conducted on operating cells. The open cell voltage $(\mathrm{OCV})$ is an accurate measurement of the humidity level in the hydrogen fuel for well-sealed cells with precise temperature measurements. Good agreement was observed between the open cell voltage and the calibrated steam content for up to $80 \%$ steam. 


\subsection{Oxygen-electrode test method development}

Component tests on the oxygen-electrode were developed in order to isolate the performance of that electrode independent of the rest of the fuel cell. A test method was developed for oxygenelectrode developed based on electrochemical impedance spectroscopy (EIS) [12, 13]. Conventional EIS of oxygen-electrodes in air is a rapid, versatile tool for evaluating ohmic and polarization losses in electrode structures as a function of temperature, oxygen pressure and bias voltage. The impedance spectra can be fit using circuit models to identify the causes of the performance losses which can be verified through correlations with microstructural observations.

Given that the IV curves of the baseline materials set are not symmetric with respect to bias voltage, the characterization must focus on the performance of electrodes under bias conditions in both the electroly-sis and power generation modes in order to evaluate their reversibility. The samples for single atmosphere air EIS were electrode structures fabricated on dense, thick electrolytes in both symmetric dual-sided geometries and three electrode geometries with reference electrodes. Specimens were designed for accurate measurement with reference electrodes.

An example of preliminary results on symmetric dual-sided test specimen is shown in Fig. 2-2. LSM/YSZ electrodes were screen-printed and sintered on opposite sides of a YSZ electrolyte. Gold mesh current collectors were provided with an LSM bondpaste to both electrodes. ASR was determined at 5 different temperatures from the difference in the low frequency and high frequency intercepts on a Nyquist plot. The error for repeated measurements within each sample and between two samples is indicated on the plot and was found to be acceptable. Optimization of the current collector processing was responsible for the precise measurements.

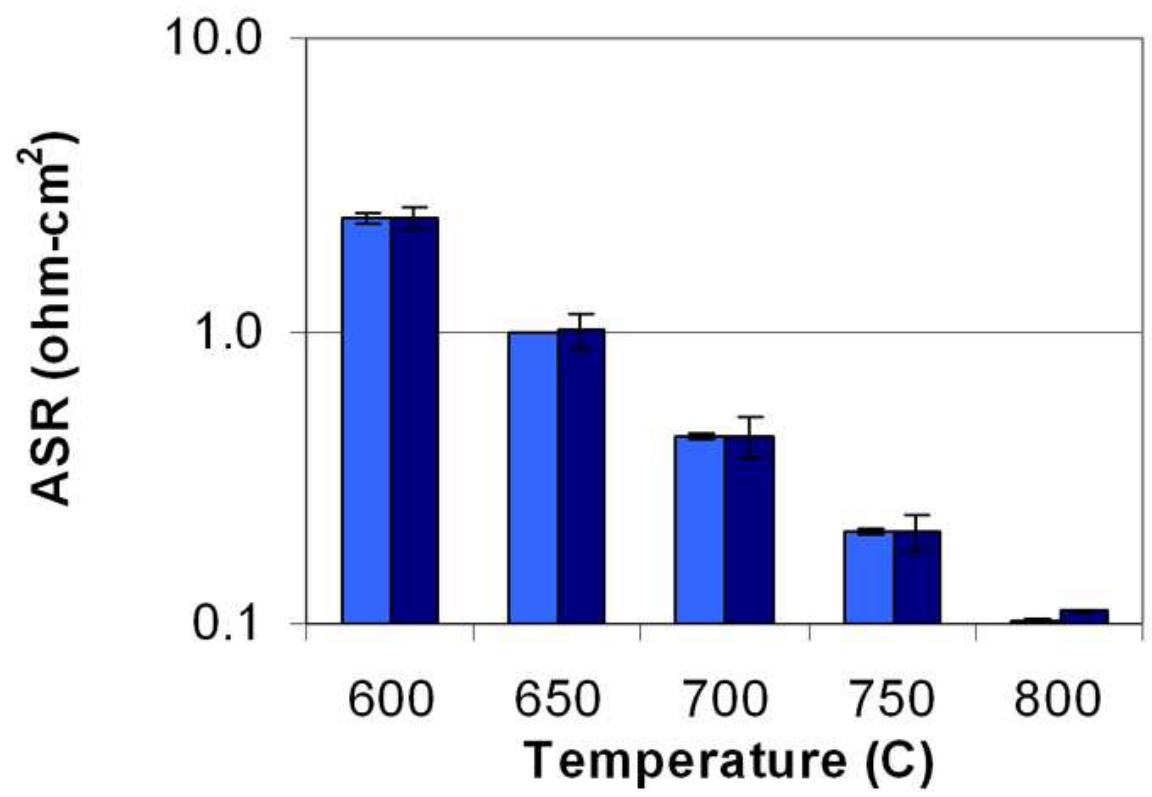

Figure 2-2. Area-specific-resistance (ASR) as a function of temperature of two sets of symmetric dual-sided electrode specimens indicating good reproducibility within a test and between specimens. 
The symmetric mode test is valuable for establishing the performance of electrodes at a reference condition that does not include the electrochemical bias. The relative performance of materials and microstructures can be rapidly and precisely determined. However, to evaluate the performance of materials specifically in electrolysis or fuel cell mode, an asymmetric test geometry is required in which electrochemical bias can be applied.

Test geometries for asymmetric EIS samples require careful design for the placement of the reference electrode to avoid errors from field effects. [14]. A customized modeling tool was developed to predict the specimen error as a function of materials parameters and geometrical dimensions. A schematic of the specimen geometry is given in Fig. 2.3a. The critical design parameter is the offset distance of the working electrode to the counter electrode $(\Delta)$ relative to the thickness of the electrolyte $\left(\delta_{\mathrm{YSZ}}\right)$. The specimen design parameters include the resistivity and thickness of the working electrode, counter electrode, and electrolyte as well as the distance from the reference electrode to the edge of the working electrode.

A three-dimensional finite element model was developed to evaluate the field line distribution within the electrolyte as a function of bias for both the high frequency and low frequency limits. An example of the field line distribution for a sample design with minimal error is given in Fig. $2.3 \mathrm{~b}$ for the high frequency limit and Fig. 2.3c for the low frequency limit. In both cases the field lines did not significantly affect the potential of the reference electrodes for the ratio of offset distance to electrolyte thickness that was chosen.

a)

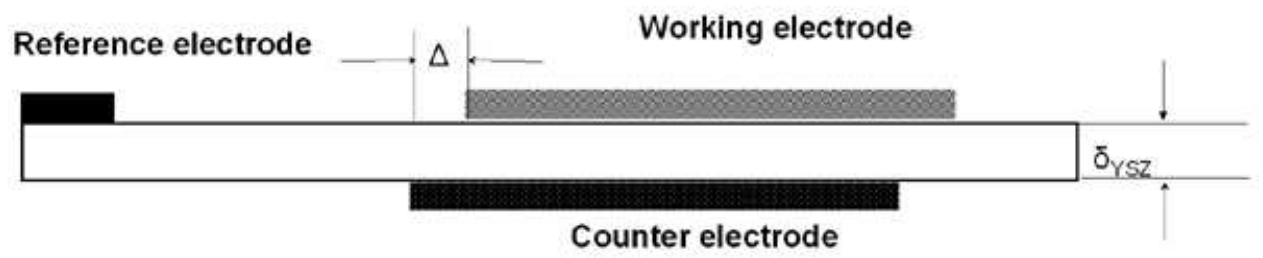

b)

High Frequency

$8.00 e-01$

$8.00 e-01$

$7.00 e-01$

$6.00 \mathrm{e}-01$

$5.00 e-01$

$4.00 e-01$

c)

Low Frequencv

$3.00 e-01$

$2.00 e-01$

$1.00 e-01$

$0.00 \mathrm{e}+00$

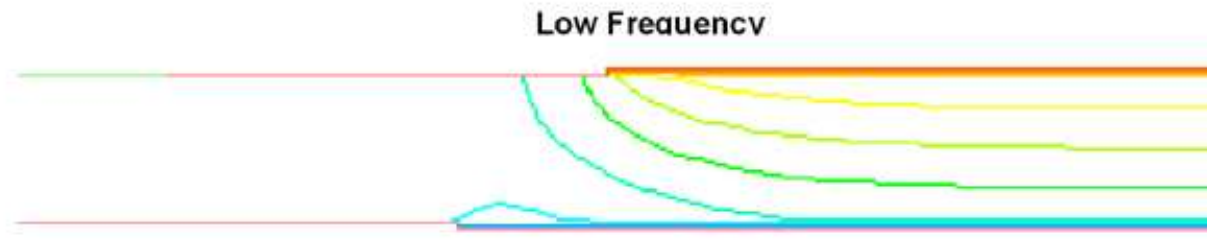

Figure 2-3 a) Schematic of geometry of asymmetric test specimen. b) Example of field line distributions for the high frequency limit. c) Example of field line distributions for the low frequency limit. 
An example of the quantitative estimation of the relative error is shown in Fig. 2.4 as a function of the ratio of offset distance to electrolyte thickness. The case was for a $200 \mu \mathrm{m}$ thick electrolyte, with working and counter electrode lengths of $8 \mathrm{~mm}$ and a distance between the working electrode and reference electrode of $600 \mu \mathrm{m}$. The analysis indicates that in order to produce a sample with less than $10 \%$ relative error, the manufacturing tolerance on the offset distance is $20 \mu \mathrm{m}$.

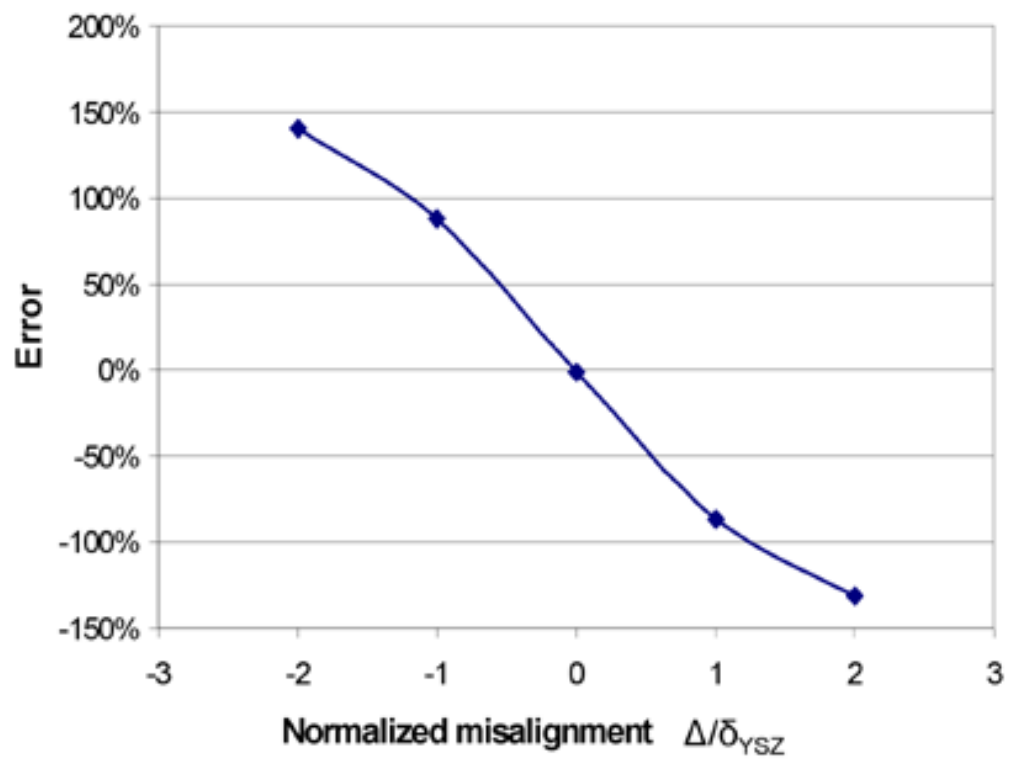

Figure 2-4. Performance curve of button cells with two different hydrogen electrodes from the baseline materials set, and the associated area-specific-resistances (ASRs). 


\section{CONCLUSION}

Two test methods were developed for evaluation of reversible electrode materials: the button cell test and the oxygen electrode test. The button cell test evaluates the performance and degradation of full solid oxide cells with dual atmosphere of air and hydrogen-steam. The oxygen electrode test is a test in air that isolates the performance and degradation of the oxygen electrode. It has higher throughput and sensitivity than the button cell test.

A button cell test methodology for reversible performance was developed. Methods for the quantification of steam content were developed and validated. Stability of the measurements over short time periods was demonstrated for measurements in both modes.

An oxygen electrode test structure was designed. A planar geometry specimen with symmetric electrodes was extended to include a reference electrode in order to allow testing under both a forward (power generation) and a reverse (electrolysis) bias. A 3-D finite element model was developed to predict the accuracy of the design for the materials and geometries of interest. Fabrication methods were developed for accurate placement of the reference electrode, working electrode and counter electrode. Accuracies of better than $10 \%$ were predicted. In addition, a method for making electrical contacts that would not introduce experimental error was demonstrated. A strategy for screening new oxygen electrodes optimized for electrolysis was developed. 


\section{ACKNOWLEDGMENTS}

This material is based upon work supported by the Department of Energy under Award Number DE-FC36-05GO15025. This work was based on the technical contributions of Jian Wu, Badri Ramamurthi, Greg Parker, Hongmei Zhang, and Todd Striker. Helpful discussions with Stephane Renou and Scott Barnett are appreciated. 


\section{REFERENCES}

1. R. Steinberger-Wilckens, L.G.J. de Haart, I.C. Vinke, L. Blum, A. Cramer, J. Remml, G. Blass, F. Tietz, W.J. Qaudakkers, in Solid Oxide Fuel Cells VIII, H. Yokokawa and S.C. Singhal, ed., PV 2003-07, 98, The Electrochemical Society Proceedings Series, Pennington, NJ, (2003).

2. B. Borglum, J.-J. Fan, E. Neary in Solid Oxide Fuel Cells VIII, H. Yokokawa and S.C. Singhal, ed., PV 2003-07, 60, The Electrochemical Society Proceedings Series, Pennington, NJ, (2003).

3. J.-W. Kim, A.V. Virkar, K-Z. Fung, K. Mehta, and S.C. Singhal, J. Electrochem. Soc.,146, 69 (1999).

4. T. Tsai and S.A. Barnett, Solid State Ionics, 93, 207 (1997).

5. W. Kreuter and H. Hoffmann, Int. J. Hydrogen Energy, 23, 661 (1998).

6. W. Doenitz and E. Erdle, Advances in Hydrogen Energy, 2, (Pergamon Press, NY) 767 (1984).

7. K. Eguchi, T. Hatagishi, and H. Arai, Solid State Ionics 86-88, 1245 (1996).

8. S.P. Jiang and J.G. Love, Solid State Ionics 158, 45 (2003).

9. A. Yamashita, H. Tsukuda, T. Hashimoto, in: U. Bossel (Ed.),Proc. 1st European Solid Oxide Fuel Cells Forum, European Fuel Cells Group, Lucerne, Switzerland, 1994, p. 661.

10. Y. Jiang, S. Wang, Y. Zhang, J. Yan, and W. Li, J. Electrochem. Soc., 145, 373 (1998).

11. A. Momma, T. Kato, Y. Kaga, and S. Nagata, J. Ceram. Soc. Japan, 105, 369 (1997).

12. S.P. Jiang, J.G. Love, and S.P.S. Badwal, Key Engineering Materials, 125-126, 81 (1997).

13. E.P. Murray, T. Tsai, and S.A. Barnett, Solid State Ionics, 110, 235 (1998).

14. J. Winkler, P.V. Hendriksen, N. Bonanos, and M. Mogensen, J. Electrochem. Soc., 145, 1184 (1998). 